American Journal of Applied Sciences 9 (3): 327-330, 2012

ISSN 1546-9239

(C) 2012 Science Publications

\title{
Residual Chromium in Leather by Instrumental Neutron Activation Analysis
}

\author{
${ }^{1}$ Okoh, S., ${ }^{1}$ I.O. Okunade, ${ }^{1}$ D.J. Adeyemo, \\ ${ }^{1}$ Y.A. Ahmed, ${ }^{2}$ A.A. Audu and ${ }^{3}$ E. Amali \\ ${ }^{1}$ Centre for Energy Research and Training, Ahmadu Bello University, Zaria, Nigeria \\ ${ }^{2}$ Department of Pure and Industrial Chemistry, \\ Faculty of Science, Bayero University, Kano Nigeria \\ ${ }^{3}$ Institute for Chemical and Leather Technology, Zaria Nigeria
}

\begin{abstract}
Problem statement: Most tanning processes employ the use of chromium sulphate. For chromium tanned leather, finished products may contain high amount of residual chromium. This may pose some health hazards, since chromium is known to be toxic at elevated concentration. This justifies the need for the study. Approach: Various samples of leather were collected from a tannery, a leather crafts market, a leather dump site and from local tanners all in Kano, Nigeria in 2009. The samples were irradiated for $6 \mathrm{~h}$ in the inner site of the Nigerian Research Reactor (NIRR-1) at a flux of $5 \times 10^{11} \mathrm{ncm}^{-2} \mathrm{sec}^{-1}$. Results: After evaluating the spectrum, the mean results for chromium in the samples were determined as $2.33 \pm 0.3,2.23 \pm 0.3$ and $2.93 \pm 0.4 \%$ for samples from the tannery, leather crafts market and leather dump sites respectively. Chromium concentration in samples collected from local tanners who use tannins from Acacia nilotica as tanning agent was below the detection limit of Instrumental Neutron Activation Analysis (INAA) technique used in the study. Conclusion: Although, the concentrations of chromium in the analysed samples were not much higher than what were obtained in literature, they may be enough to sensitize the population that is allergic to chromium.
\end{abstract}

Key words: Chrome tanning, chromium concentration, local tanners, acacia nilotica, Instrumental Neutron Activation Analysis (INAA), chromium sulphate, health hazards

\section{INTRODUCTION}

Leather industry provides the necessities, such as leather shoes and garments using the bye-products of the meat industry (Mu et al., 2003). The material called leather is obtained by the conversion of hides and skins through a treatment process known as tanning (Bienkiewicz, 1983). The tanning process involves specific reactions among carboxylic groups of the protein fiber network of animal skin (collagen) and tanning agents. The various method of tanning include vegetable tanning, aldehyde tanning, chrome tanning, alum tanning or iron tanning. However, the two major approaches to tanning are vegetable and chrome tanning US EPA, 1997. Vegetable tanning, which uses aqueous infusions of polyphenolic materials of plant origin, has been the most important tanning method until the advent of chrome tanning. Today, around 90\% of the global leather production uses the conventional chrome tanning process for tanning leather (Rezic and Zeiner, 2009). The conventional chrome tanning process employs the use of basic chromium sulphate (Rao et al., 2004). The problem with this process lies in the fact that, after the wood preservation industry, the leather industry uses the highest amounts of chromium chemicals which afterwards are released into the environment or remain in and on the product (Rezic and Zeiner, 2009).

The two oxidation states of Chromium (Cr (III) and $\mathrm{Cr}(\mathrm{VI}))$ are directly linked to its nutritional and toxic effects. While $\mathrm{Cr}$ (III) is an essential element as a result of its role in glucose, lipid and protein metabolism, $\mathrm{Cr}$ (VI) is highly toxic with a large aqueous solubility (Langard, 1982). Indeed, Cr (VI) is highly carcinogenic and causes damage to skin, mucous membrane and respiratory tract.

It has been estimated that the prevalence of chromium allergy in the general population is between 0.5 and $1.7 \%$ (Nielsen et al., 2000; Peltonen and Fraki, 1983). In consecutive patients with eczema, studies have shown prevalence Fig. 1 from 1.8-7.5\% (Johansen et al., 2002; Lestringant et al., 1999). 
Am. J. Applied Sci., 9 (3): 327-330, 2012

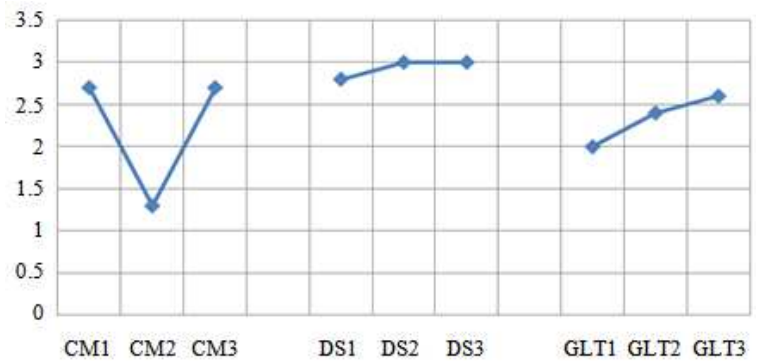

Fig. 1: A graph of the concentration range of chromium in the leather samples

Even though Cr (III) has low water solubility than $\mathrm{Cr}$ (VI) and only a small fraction will penetrate into the skin, it can still elicit allergic reactions at certain concentrations. No lower threshold is known, but $46 \%$ of chromium allergic patients reacted to $1.5 \%$ when patch tested (Hansen et al., 2002).

In the city of Kano, Nigeria, there are several Leather Tanning Industries that process hides and skins for both local and international markets. Since these industries use chromium salts for the tanning process, it is inevitable that leather products from these industries will contain residual chromium, hence the need for the present study. INAA is a method of choice for analysis of chromium in biological samples. Nigerian Research Reactor (NIRR-1) is particularly suitable for analysis of biological specimen because the average mean temperature at the irradiation channels is about $50^{\circ} \mathrm{C}$ thus leading to minimal volatilization losses. In addition INAA is highly sensitive, non-destructive and only requires minimum sample preparation of the specimen (Ahmed et al., 2010).

\section{MATERIALS AND METHODS}

Sampling and sample preparation: The samples used for the present study include (i) locally tanned leathers bought from local tanners in the ancient city of Kano and labeled LT (ii) leather samples collected from a tannery in Kano labeled GL (iii) samples collected from a popular craft market in Kano where leather materials are crafted for different purposes labeled CM (iv) leather materials collected from a dump site where leather solid wastes are dumped by different tanneries labeled DS.

The Leather samples were cut into small pieces and weighed using an analytical balance (Mettler AE 240 ) to obtain between 0.3-0.5 g of each sample. Each sample was sealed in polythene bags that had been precleaned with distilled water and dilute $\mathrm{HCl}$. The polythene bags containing the leather samples were then secured inside sample vials (that were rinsed with distilled water and allowed to dry in an oven at a maintained temperature of $60^{\circ} \mathrm{C}$ for $2 \mathrm{~h}$ ), with sterilized cotton wool, covered and cello-taped, ready for irradiation.

Specimen irradiation and counting: The irradiation vials containing the leather samples were irradiated using the Nigeria Research Reactor-1 (NIRR-1) located at the Centre for Energy Research and Training, Ahmadu Bello University, Zaria Nigeria. Since chromium produce long-lived nuclides, the irradiation was performed for $6 \mathrm{~h}$ in the inner channels B2 where the magnitude of thermal neutron flux is the highest. After the irradiation, gamma-ray measurements were performed at sample-detector geometry of $1 \mathrm{~cm}$ for 60 min after a waiting period of 10 days. The choice of cooling time and sample-detector geometry were aimed at limiting dead time to less than $10 \%$. A detailed description of the irradiation and gamma ray counting protocols for short and long irradiation for NIRR-1 can be found in (Jonah et al., 2006). Counting of induced gamma rays in the activation products were carried out using PC-based gamma-ray spectrometry set up which consists of a horizontal dip-stick High-Purity Germanium (HPGe) detector having relative efficiency of $10 \%$ at $133.5 \mathrm{KeV}$, the MAESTRO emulation software compatible with the $\mathrm{ADCAM}^{(\mathrm{R})}$ Multi-Channel Analyzer (MCA) card, associated electronic modules and a personal computer. Identification of gamma-ray fingerprint of product radio-nuclides through their energies and quantitative analysis procedure for determination of their concentrations were achieved using the gamma-ray analysis software WINSPAN 2004.

\section{RESULTS}

Table 1 shows the analysis results for chromium levels in leather samples from Kano, Nigeria. The results indicate that mean chromium concentration ranged from $2.23-2.93 \%$ in the various leather samples monitored. Mean chromium concentration in the samples were in the order of magnitude CM $<$ GLT $<$ DS. However, chromium concentration in leather samples from local tanners was below the detection limit of 1.6 $\mathrm{mg} \mathrm{kg}^{-1}$ (Jonah et al., 2006) of INAA technique used.

\begin{tabular}{lll}
\multicolumn{2}{l}{ Table 1: Concentration of chromium in leather samples from Nigeria } \\
\hline Leather sample & $\begin{array}{l}\text { Concentration } \\
\text { range of } \mathrm{Cr}(\mathrm{wt} \%)\end{array}$ & $\begin{array}{c}\text { Mean concentration } \\
\text { of Cr (wt \%) }\end{array}$ \\
\hline CM & $1.3-2.7$ & $2.23 \pm 0.27$ \\
DS & $2.8-3.0$ & $2.93 \pm 0.37$ \\
GL & $2.0-2.6$ & $2.33 \pm 0.30$ \\
LT & BDL & BDL \\
\hline
\end{tabular}

$\mathrm{BDL}=$ Below Detection Limit 


\section{DISCUSSION}

The mean chromium concentration which ranged from $2.23-2.93 \%$ in the chrome tanned leathers were within most literature values. The chromium concentration for samples of local tanned leathers on the other hand, were below the detection limit of 1.6 $\mathrm{mg} \mathrm{kg}^{-1}$.

This can be attributed to the fact that local tanners use tannins from Acacia nilotica for the tanning process. It has been demonstrated by Haensel et al., (2008) that vegetable tanned leather may contain trace concentration of chromium. This was further corroborated by the findings in a study involving 21 shoe samples from 6 countries in which the leather samples analyzed showed elevated concentration of chromium in all except for one of the samples that was characterized with chromium concentration of $5.8 \mathrm{mg} \mathrm{kg}{ }^{-1}$ which was associated with vegetable tanning Swedish Society for Nature Conservation, 2009 (Haensel et al., 2008). Residual chromium content associated with chrome tanning had been previously determined to fall within the range of 0.68-3.42\% ASTM 2003.

This is consistent with the results shown in Table 1 , in which chromium concentration in chrome tanned leather lies between 1.3 and $3.0 \%$, showing that chromium occurs in chrome tanned leather at elevated concentration. As stated previously, $\mathrm{Cr}$ (VI) is the one that is said to constitute major health hazards. Its origin in leather has been attributed to the presence of incompletely reduced chromium tanning agents such as combustion of $\mathrm{Cr}$ (III)-bearing leather and possible oxidation of $\mathrm{Cr}$ (III) to $\mathrm{Cr}$ (VI) during air exposure. In addition, research findings have shown that aftermath treatments of leather including neutralization, dyeing, fat-liquoring and re-tanning provide significant contribution to the concentration of $\mathrm{Cr}$ (VI) when small changes in these processes between different batches of leather occurs (Graf, 2001; Hauber and Germann, 1999). The elevated concentration of chromium determined in study is thus likely to have significant $\mathrm{Cr}$ (VI) constituent. However, further research involving speciation studies of chromium in leather need to be carried out to firmly establish this claim. The elevated concentration of chromium found in study still exceeds the threshold of $1.5 \%$ that caused allergic reactions in the previous study by (Hansen et al., 2002) an indication that adequate control measures is required to be instituted to limit residual chromium levels in leather samples produced in Nigeria.

\section{CONCLUSION}

Neutron Activation Analysis has been used to determine chromium concentrations in leather samples produced in Kano-Nigeria. The mean chromium concentrations ranged from $1.30-3.0 \%$ for the chrome tanned leather while chromium levels in vegetable tanned leather was less than the INAA detection limit of $1.6 \mathrm{mg} \mathrm{kg}$. $^{-1}$ The elevated level of chromium determined in study may presuppose the presence of the more toxic $\mathrm{Cr}(\mathrm{VI})$ in the leather which usually originates from partial combustion of $\mathrm{Cr}$ (III)-bearing leather and possible oxidation of $\mathrm{Cr}$ (III) to $\mathrm{Cr}$ (VI) during air exposure. Although, the concentrations of chromium in the analysed samples were not much higher than what were obtained in literature, they may be enough to sensitize the population that is allergic to chromium.

The carcinogenic nature and other health effects associated with $\mathrm{Cr}$ (VI) therefore imposes a responsibility of further studies of $\mathrm{Cr}$ (VI) in leather samples to protect the population from avoidable health risks.

\section{ACKNOWLEDGEMENT}

The researchers are grateful to the Centre for Energy Research and Training, Ahmadu Bello University Zaria-Nigeria, who provided the facilities that were used for the study. Also, the cost of publication was borne by the Centre for which the authors are appreciative.

Mr. Alhassan A Jaoji and Shehu Umar are hereby acknowledged for their assistance in sample preparation.

\section{REFERENCES}

Ahmed, Y.A., S. Landsberger, D.J O'Kelly, J. Braisted and H. Gabdo et al., 2010. Compton suppression method and epithermal NAA in the determination of nutrients and heavy metals in Nigerian food and beverages. Applied Radiation Isotopes, 68: 19091914. DOI: 10.1016/j.apradiso.2010.04.016

Bienkiewicz, K.J., 1983. Physical Chemistry of Leather Making. 1st Edn., Krieger Pub. Co., Malabar, ISBN: 0898743044, pp: 541.

Graf, D., 2001. Formation of $\mathrm{Cr}(\mathrm{VI})$ traces in chrome tanned leathers causes, prevention and latest findings. J. Am. Leather Chemists'Asso., 96: 169179.

Hansen, M.B. S. Rydin, T. Menne and J.D. Johanson, 2002. Quantitative aspects of contact allergy to chromium and exposure to chrome-tanned leather. Contact Dermatitis, 47: 127-134. DOI: 10.1034/j.1600-0536.2002.470301.x 
Haensel, A., P.J. Mills, R.A. Nelesen, M.G. Ziegler and J.E. Dimsdale, 2008. The relationship between heart rate variability and inflammatory markers in cardiovascular diseases. Psychoneuroendocrinology, 33: 1305-1312. DOI: 10.1016/j.psyneuen.2008.08.007

Hauber, C. and H.P. Germann, 1999. Investigations on a possible formation and avoidance of chromate in leather. World Leather, 12: 73-73.

Johansen, J.D., T. Menne, J. Christophersen, K. Kaaber and N. Veren, 2002. Changes in the pattern of sensitization to common contact allergens in Denmark between 1985-86 and 1997-98, with a special view to the effect of preventive strategies. Bri. J. Dermatol., 142: 490-495. DOI: 10.1046/j.1365-2133.2000.03362.x

Jonah, S.A., I.M. Umar, M.O.A. Oladipo, G.I. Balogun and D.J. Adeyemo, 2006. Standardization of NIRR-1 irradiation and counting facilities for instrumental neutron activation analysis. Applied Radiation Isotopes, 64: 818-822. DOI: 10.1016/j.apradiso.2006.01.012

Lestringant, G.G., A. Bener, M. Sawaya, I.H. Galadari and P.M. Frossard, 1999. Allergic Contact dermatitis in the United Arab Emirates. Int. J. Dermatol., 38: 181-186. DOI: 10.1046/j.13654362.1999.00628.x
Langard, S., 1982. Biological and Environmental Aspects of Chromium. 1st Edn., Elsevier Biomedical Press, Amsterdam, New York, pp: 285.

Mu, C., W. Lin, M. Zhang and Q. Zhu, 2003. Towards Zero discharge of chromium-containing leather waste through improved alkali hydrolysis. Waste Manage., 23: 835-843. DOI: 10.1016/S0956053X(03)00040-0

Nielsen, N.H., J. Kristiansen, L. Borg, J.M. Christensen and L.K. Poulsen et al., 2000. Repeated exposures to cobalt or chromate on the hands of patients with hand eczema and contact allergy to that metal. Contact Dermatitis, 43: 212-215. DOI: 10.1034/j.1600-0536.2000.043004212.x

Peltonen, L. and J. Fraki, 1983. Prevalence of dichromate sensitivity. Contact Dermatitis, 9: 190-194. DOI: 10.1111/j.1600-0536.1983.tb04356.x

Rao, J.R., M. Kanthimathi, P. Thankaivelan, K.J. Sreeram and R. Ramesh et al., 2004. Pickle-free chrome tanning using a polymeric synthetic tanning agent for cleaner leather processing. Clean Techn. Environ. Policy, 6: 243-249. DOI: 10.1007/s10098-003-0240-9

Rezic, I. and M. Zeiner, 2009. Determination of extractable chromium from leather. Monatsh Chem. 140: 325-328. DOI: 10.1007/s00706-008-0026-1 